(2) Open Access Full Text Article

\title{
A quality of life study comparing scleral buckle and pneumatic retinopexy for the treatment of rhegmatogenous retinal detachment
}

This article was published in the following Dove Press journal:

Clinical Ophthalmology

6 June 2017

Number of times this article has been viewed

\section{Angela C Gauthier \\ Ron A Adelman}

Department of Ophthalmology and Visual Science, Yale School of Medicine, New Haven, CT, USA
Correspondence: Angela C Gauthier

Yale Eye Center, 40 Temple Street,

New Haven, CT 065I0, USA

Tel + I 2037852020

Fax + I 0 II 2037857090

Email angela.gauthier@yale.edu

\section{Introduction}

Patients who have undergone surgical treatment for retinal detachment may have significantly impaired visual-related quality of life. ${ }^{1}$ Although there are many studies that compare the visual outcomes and anatomical success of scleral buckle and pneumatic retinopexy in treating retinal detachment, there are inadequate data contrasting quality of life measures between these two approaches. ${ }^{2,3}$ A recent Cochrane review found that patients who underwent pneumatic retinopexy may be more likely to have recurrence of detachment but less likely to have choroidal detachment or a myopic shift than those who had scleral buckle. ${ }^{4}$ They concluded that there is still a dearth of important patient-centered information such as quality of life outcomes with these procedures. ${ }^{4}$ This study aimed to compare quality of life between patients who underwent scleral buckle or pneumatic retinopexy for treatment of rhegmatogenous retinal detachment.

\section{Methods}

Patients who underwent either scleral buckle or pneumatic retinopexy for rhegmatogenous retinal detachment at the Yale Eye Center between January 1993 and December 2013 were identified. A modified version of the National Eye Institute Visual Function Questionnaire-25 (VFQ-25) was administered by mail or phone interview to patients within 8 years after their surgery. ${ }^{5}$ For data received from respondents, results were calculated by subgroup analysis of the VFQ-25, independent two-tailed $t$-test, and a chi-squared test.

The study was reviewed and approved by the Yale University Institutional Review Board, which found that written informed consent could be waived because the research presented no more than minimal risk of harm to subjects. All subjects were provided an information sheet or given verbal information that described the risks and benefits of the study, and the decision to participate in the survey was considered consent.

\section{Results}

Fifty-nine patients participated in the survey, including 31 scleral buckle patients and 28 pneumatic retinopexy patients. There was no difference in VFQ-25 composite scores between scleral buckle (78.9 \pm 19.0$)$ and pneumatic retinopexy $(81.1 \pm 19.0)$ patients $(P=0.64)$. Both groups scored similarly in general health, general vision, ocular 
Table I VFQ-25 subscale scores for scleral buckle and pneumatic retinopexy

\begin{tabular}{|c|c|c|c|c|c|}
\hline \multirow[t]{2}{*}{$\begin{array}{l}\text { VFQ-25 } \\
\text { subscale score }\end{array}$} & \multicolumn{2}{|c|}{ Mean (standard deviation) } & \multicolumn{2}{|c|}{$\begin{array}{l}95 \% \text { confidence } \\
\text { interval of the } \\
\text { difference }\end{array}$} & \multirow[t]{2}{*}{$P$-value } \\
\hline & $\begin{array}{l}\text { Scleral buckle } \\
(\mathrm{N}=31)\end{array}$ & $\begin{array}{l}\text { Pneumatic } \\
\text { retinopexy }(\mathrm{N}=28)\end{array}$ & Lower & Upper & \\
\hline General health & $66.9(25.3)$ & $73.2(25.4)$ & -19.5 & 7.0 & 0.35 \\
\hline General vision & $71.8(14.3)$ & 75.7 (I5.7) & -11.7 & 3.9 & 0.33 \\
\hline Ocular pain & $76.6(23.9)$ & $82.6(21.1)$ & -17.8 & 5.8 & 0.31 \\
\hline Near activities & $79.3(21.4)$ & $75.1(20.7)$ & -6.8 & 15.1 & 0.45 \\
\hline Distance activities & $77.6(21.0)$ & $81.0(20.0)$ & -14.1 & 7.3 & 0.53 \\
\hline Social functioning & $89.9(20.0)$ & $92.0(17.1)$ & -11.8 & 7.7 & 0.68 \\
\hline Mental health & $71.4(28.5)$ & $79.0(24.0)$ & -21.5 & 6.2 & 0.27 \\
\hline Role difficulty & $72.7(20.2)$ & $77.2(25.9)$ & -16.5 & 7.5 & 0.46 \\
\hline Dependency & $88.0(24.3)$ & $90.6(24.1)$ & -15.2 & 10.1 & 0.68 \\
\hline Driving & $74.9(21.3)$ & $75.0(27.0)$ & -12.8 & 12.5 & 0.98 \\
\hline Color vision & $94.8(16.4)$ & $93.3(16.1)$ & -7.0 & 9.9 & 0.73 \\
\hline Peripheral vision & 71.5 (28.7) & $72.3(28.3)$ & -15.8 & 14.0 & 0.91 \\
\hline
\end{tabular}

Notes: The VFQ-25 consists of 25 questions that ask the patient to rate their general health and vision, the difficulty of completing different tasks because of vision limitations, and how well they have responded to their level of vision. Questions are assigned to one of 12 subscales. Each item is translated to a score from 0 to 100 , with 100 being the best functioning. Scores from questions within each subscale are averaged together to create a score from 0 to 100 for each subscale. Finally, a composite score for the VFQ-25 is calculated by averaging all of the subscale scores, except the general health rating question. No significant differences were found for any of the subscale scores.

Abbreviation: VFQ-25, National Eye Institute Visual Function Questionnaire-25.

pain, near activities, distance activities, social functioning, mental health, role difficulties, dependency, driving, color vision, and peripheral vision (Table 1). Also, there were no significant differences found for any of the additional postoperational questions (Table 2). There was a trend toward a higher percentage $(85 \%)$ of pneumatic retinopexy patients preferring to have the same procedure in their fellow eye compared to scleral buckle patients $(59 \%, P=0.06)$.

\section{Discussion}

These findings suggest that patients who had scleral buckle or pneumatic retinopexy treatment have a similar postoperative quality of life. Indeed, primary and overall surgical success rates appear to be similar in the two treatments. ${ }^{6,7}$ In addition, studies have generally found comparable final visual acuity outcomes in patients with uncomplicated rhegmatogenous retinal detachment. ${ }^{2}$

Although this effect did not reach statistical significance due to small sample size, it is interesting that a much lower proportion of scleral buckle patients than pneumatic retinopexy patients may choose to repeat the procedure, although both groups now enjoy similar levels of quality of life. Pneumatic retinopexy is a newer, quicker, less expensive, and less invasive procedure than scleral buckle. ${ }^{8,9}$ Perhaps the

Table 2 Additional question scores for scleral buckle and pneumatic retinopexy

\begin{tabular}{|c|c|c|c|c|c|}
\hline \multirow[t]{2}{*}{ Additional questions } & \multicolumn{2}{|c|}{ Mean (standard deviation) } & \multicolumn{2}{|c|}{$\begin{array}{l}95 \% \text { confidence } \\
\text { interval of the } \\
\text { difference }\end{array}$} & \multirow[t]{2}{*}{$P$-value } \\
\hline & $\begin{array}{l}\text { Scleral buckle } \\
(\mathrm{N}=29)\end{array}$ & $\begin{array}{l}\text { Pneumatic } \\
\text { retinopexy }(\mathrm{N}=26)\end{array}$ & Lower & Upper & \\
\hline Difficulty with activities & $2.9(1.9)$ & $2.7(2.1)$ & -0.8 & 1.4 & 0.61 \\
\hline Limitations & $2.7(1.8)$ & $2.8(2.2)$ & -1.2 & 0.9 & 0.78 \\
\hline Pain & $2.3(2.4)$ & $2.0(2.2)$ & -0.9 & 1.5 & 0.62 \\
\hline Early pain & $4.2(3.0)$ & $3.7(2.6)$ & -1.0 & 2.1 & 0.49 \\
\hline Pain 48 hours postoperative & $5.3(3.1)$ & $4.4(3.2)$ & -0.8 & 2.6 & 0.29 \\
\hline Difficulty postoperative & $5.3(2.8)$ & $4.9(3.0)$ & -1.2 & 1.9 & 0.66 \\
\hline Resume normal activity (weeks) & $3.4(1.5)$ & $3.1(1.2)$ & -0.5 & 1.0 & 0.46 \\
\hline Choosing the same operation (\%) & 59 & 85 & NA & NA & 0.06 \\
\hline
\end{tabular}

Notes: Eight questions were added to the VFQ-25 in order to create a modified survey targeted to patients who have undergone retinal detachment procedures. Scores ranged from I to 10, with higher numbers indicating increased difficulty or pain. No significant differences were found for any of the questions, but chi-squared analysis revealed a trend toward a higher percentage of patients choosing the same procedure for their fellow eye in the pneumatic retinopexy group compared to the scleral buckle group $(P=0.06)$.

Abbreviations: VFQ-25, National Eye Institute Visual Function Questionnaire-25; NA, not applicable. 
differences in likelihood to reelect the procedure are due to factors not assessed in this survey. In addition, it is possible that there exist postoperative pain and recovery differences between the groups, but they simply did not reach statistical significance due to sample size. If pneumatic retinopexy patients experienced an easier recovery than patients in the scleral buckle group, it may explain why they are more likely to choose the procedure again.

A few limitations of this study can be identified. For example, patients completed surveys at variable times up to 8 years following their surgeries given the study's retrospective design. In addition, we excluded patients who underwent reoperation for subsequent retinal detachment, as our primary endpoint focused on those patients who underwent one of two single procedures. The sample size of 59 patients is relatively small because many patients with uncomplicated rhegmatogenous retinal detachment undergo vitrectomy or a combination of procedures. Future work involving a larger patient cohort, randomization to scleral buckle or pneumatic retinopexy in a prospective fashion, and multi-institutional collaboration may further elucidate quality of life measures depending on the specific surgical approach. We also suggest administering the VFQ-25 both pre- and postoperatively to better compare patients' baseline with follow-up opinions on their vision quality of life.

\section{Conclusion}

Patients who had scleral buckle or pneumatic retinopexy had a similar postoperative quality of life, although scleral buckle is more invasive. However, there was a trend toward a higher percentage of patients preferring to have the same procedure on their fellow eye in the pneumatic retinopexy group than the scleral buckle group, suggesting that quality of life is not the only factor that determines patient preferences.

\section{Acknowledgments}

We would like to acknowledge Modjtaba Amirahmadi, MD, for his help with data collection. This project was supported by Leir Foundation, Newman's Own Foundation, Research to Prevent Blindness, and Grant Number T35HL007649 from the National Heart, Lung and Blood Institute. The content is solely the responsibility of the authors and does not necessarily represent the official views of the National Heart, Lung, and Blood Institute or the National Institutes of Health.

\section{Author contributions}

All authors contributed toward data analysis, drafting and critically revising the paper and agree to be accountable for all aspects of the work.

\section{Disclosure}

The authors report no conflicts of interest in this work.

\section{References}

1. Smretschnig E, Falkner-Radler CI, Binder S, et al. Vision-related quality of life and visual function after retinal detachment surgery. Retina. 2016; 36(5):967-973.

2. Saw SM, Gazzard G, Wagle AM, Lim J, Au Eong KG. An evidence-based analysis of surgical interventions for uncomplicated rhegmatogenous retinal detachment. Acta Ophthalmol Scand. 2006;84(5):606-612.

3. Adelman RA, Parnes AJ, Ducournau D. Strategy for the management of uncomplicated retinal detachments: the European vitreo-retinal society retinal detachment study report 1. Ophthalmology. 2013;120(9): 1804-1808.

4. Hatef E, Sena DF, Fallano KA, Crews J, Do DV. Pneumatic retinopexy versus scleral buckle for repairing simple rhegmatogenous retinal detachments. Cochrane Database Syst Rev. 2015;(5):CD008350.

5. Mangione CM, Lee PP, Gutierrez PR, Spritzer K, Berry S, Hays RD. Development of the 25-item National Eye Institute Visual Function Questionnaire. Arch Ophthalmol. 2001;119(7):1050-1058.

6. Ellakwa AF. Long term results of pneumatic retinopexy. Clin Ophthalmol. 2012;6:55-59.

7. Schwartz SG, Kuhl DP, McPherson AR, Holz ER, Mieler WF. Twentyyear follow-up for scleral buckling. Arch Ophthalmol. 2002;120(3): 325-329.

8. Goldman DR, Shah CP, Heier JS. Expanded criteria for pneumatic retinopexy and potential cost savings. Ophthalmology. 2014;121(1): 318-326.

9. Holz ER, Mieler WF. View 3: the case for pneumatic retinopexy. $\mathrm{Br} \mathrm{J}$ Ophthalmol. 2003;87(6):787-789.
Clinical Ophthalmology

\section{Publish your work in this journal}

Clinical Ophthalmology is an international, peer-reviewed journal covering all subspecialties within ophthalmology. Key topics include: Optometry; Visual science; Pharmacology and drug therapy in eye diseases; Basic Sciences; Primary and Secondary eye care; Patient Safety and Quality of Care Improvements. This journal is indexed on

\section{Dovepress}

PubMed Central and CAS, and is the official journal of The Society of Clinical Ophthalmology (SCO). The manuscript management system is completely online and includes a very quick and fair peer-review system, which is all easy to use. Visit http://www.dovepress.com/ testimonials.php to read real quotes from published authors. 